\title{
A avaliação do visitante sobre a infraestrutura de transporte à Ilha do Combu, um atrativo turístico amazônico de Belém (PA)
}

\author{
Visitor's assessment of the transportation infrastructure to Combu Island, an Amazonian \\ tourist attraction of Belém (PA)
}

\author{
Evaluación del visitante de la infraestructura de transporte a la isla de Combu, una \\ atracción turística amazónica de Belém (PA)
}

Jamyle Cristine Abreu Aires ${ }^{1}$

Alan Carlos de Jesus Costa ${ }^{2}$ Matheus Yuri de Oliveira Rosa ${ }^{3}$ Flavio Henrique Souza Lobato ${ }^{4}$

Este artigo foi recebido em 28 de agosto de 2019 e aprovado em 09 de setembro de 2020

\begin{abstract}
Resumo: Este estudo teve como objetivo avaliar a infraestrutura dos terminais e dos meios de transporte utilizados para o deslocamento até Ilha do Combu, Belém (PA), a partir da percepção do visitante. Os procedimentos metodológicos utilizados partiram de abordagens qualitativa e quantitativa, fazendo uso de pesquisas documentais, bibliográficas e de campo. Como instrumentos de coleta de dados, foram empregadas observações sistemáticas in loco e aplicação de questionário. Os dados revelaram que as pequenas embarcações e os terminais que efetivam o transporte à Ilha do Combu apresentam precárias condições estruturais, não oferecendo segurança, comodidade e acessibilidade, sobretudo para idosos e Pessoas Com Deficiência (PCDs). Tal situação gera implicações à atividade turística desenvolvida na ilha, visto que o visitante se sente insatisfeito e temeroso com a insegurança ao qual se vê exposto.
\end{abstract}

Palavras-chave: Avaliação dos visitantes. Ilha do Combu. Infraestrutura. Transportes. Turismo.

\begin{abstract}
This study aimed to evaluate the infrastructures of the terminals and transport facilities used to travel to Ilha do Combu, Belém (PA), from visitor's perception. The methodological procedures used were based on a qualitative and quantitative approach, through documentary, bibliographic and field research. As data collection instruments, systematic in locus observations and questionnaire were applied. The data revealed that the small boats and poor structured terminals used to travel to Ilha do Combu do not offer safety, convenience and accessibility, especially for the elderly and disabled people. Such situation generates implications to the tourist activity at the Island, since the visitor feels dissatisfied and fearful with the insecurity to which he is exposed.

Key words: Combu Island. Infraestructure. Transportation. Tourism. Visitors assessment.
\end{abstract}

Resumen: Este estudio tuvo como objetivo evaluar cómo la infraestructura de los terminales y los medios de transporte solían viajar a Isla Combu, Belém (PA), desde la percepción del visitante. Los procedimientos metodológicos utilizados se basaron en enfoques cualitativos y cuantitativos, haciendo uso de la investigación documental, bibliográfica y de campo. Como instrumentos de recolección de datos, se emplearon observaciones sistemáticas en locus y aplicación de cuestionarios. Los datos revelaron que las embarcaciones pequeñas y las terminales que hacen el transporte a la isla de Combu tienen condiciones estructurales precarias, no ofrece seguridad, conveniencia y accesibilidad, especialmente para personas mayores y personas con discapacidad (PCD). Tal situación genera implicaciones negativas para la actividad turística desarrollada en la Isla, ya que el visitante se siente insatisfecho y temeroso de la inseguridad a la que está expuesto.

Palabras Clave: Calificación de visitante. Infraestructura. Isla Combu. Transportes. Turismo.

\footnotetext{
${ }^{1}$ Formação/curso: Graduanda em Turismo. Instituição: Universidade Federal do Pará (UFPA), Belém - PA, Brasil. E-mail: jamyle.aires@gmail.com.

${ }^{2}$ Formação/curso: Graduado em Turismo. Instituição: Universidade Federal do Pará (UFPA), Belém - PA, Brasil. E-mail: alan.ifpa@hotmail.com.

${ }^{3}$ InformaFormação/curso: Graduando em Tecnologia em Alimentos. Instituição: Universidade do Estado do Pará (UEPA), Belém - PA, Brasil. E-mail: matheusyurid@gmail.com.

${ }^{4}$ Formação/curso: Graduado em Turismo. Especialista em Geografia e Meio Ambiente e Mestrando em Planejamento do Desenvolvimento. Instituição: Universidade Federal do Pará (UFPA), Belém - PA, Brasil. E-mail: flaviohslobato@ gmail.com.
} 
A AVALIAÇÃO DO VISITANTE SOBRE A

INFRAESTRUTURA DE TRANSPORTE À ILHA

DO COMBU, UM ATRATIVO TURÍSTICO

AMAZÔNICO DE BELÉM (PA)
Alan Carlos de Jesus Costa Matheus Yuri de Oliveira Rosa Flavio Henrique Souza Lobato

\section{Introdução}

Com a gênese e o desenvolvimento de viagens turísticas pelo mundo, fomentadas principalmente pelas revoluções e transformações informacionais (PADILHA, 1992; PALHARES, 2003; PELIZZER, 1978), a necessidade de revolucionar os sistemas de organização dos serviços se originou. Entre tais serviços, o transporte por se configura como um dos elementos essenciais para a implementação e o desenvolvimento da atividade (BENI, 2003) e, por conseguinte, do desenvolvimento local (MARQUES, 2019; RIVEIRA, 2018), passou por mudanças substanciais. Nessa direção, Rodrigue, Comtois e Slack (2013) reiteram que, desde os 200 anos da passagem de criação dos transportes, sobretudo os mecanizados, o progresso e o desenvolvimento econômico do mundo foram sumariamente importantes para o surgimento das inovadoras tecnologias de aperfeiçoamento dos transportes. A invenção da máquina a vapor, pois, desencadeou mudanças radicais nesse período, que, por sua vez, contribuíram, sobremaneira, para aperfeiçoamentos e melhorias em termos de velocidade, de eficiência, de conforto/comodidade e, principalmente, no que concerne ao acesso das mais distantes destinações em um curto espaço-temporal (COOPER et al., 2002; MILL; MORRISON, 1985; RODRIGUE; COMTOIS; SLACK, 2013).

Esse contexto de Revolução Industrial é narrado por diversos autores como a mola propulsora do turismo (TRIGO, 1998), ao ligar de modo eficiente diferentes lugares, ao fomentar, em certa medida, a massificação ou a turistificação das destinações (GAZONI; SILVA; FORTES, 2017; LOHMANN, 2003; MILL; MORRISON, 1985; SILVA et al., 2020; POON, 1993). Tais melhorias, tampouco permitiram "[...] que a gente viaje mais rápido e mais longe", provocaram “[...] uma nova visão do mundo. O mundo passa a ser observado como paisagem, como panorâmica" (PÉREZ, 2009, p. 19). Assim, os transportes se transformam, no âmbito do turismo, em um meio dos viajantes admirarem, conhecerem e vivenciarem diferentes lugares. São, portanto, os transportes potencializadores das experiências turísticas (KRIPPENDORF, 2001; LOHMANN, FRAGA; CASTRO, 2013).

Entrementes, na atual conjuntura, tem-se uma sociedade detentora de maior conhecimento sobre seus direitos e deveres, uma sociedade mais crítica, logo, mais exigente com os produtos e serviços adquiridos (MARUJO, 2008; ROSA; SILVA; LOBATO, 2020). Nessa perspectiva, não é mais suficiente apenas se ter meios de transporte para a realização de deslocamentos, é indispensável a existência de uma infraestrutura básica, com vias de acesso em bom estado, mobilidade urbana dentro dos padrões aceitáveis, terminais (pontos de embarque e desembarque) seguros e confortáveis, pois eles representam os "nós", a passagem entre diferentes destinos e diferentes modais (LOHMANN, 2003;

Observatório de Inovação do Turismo - Revista Acadêmica

Vol. XIV n $^{\circ}$, dezembro - 2020 
A AVALIAÇÃO DO VISITANTE SOBRE A

INFRAESTRUTURA DE TRANSPORTE À ILHA

DO COMBU, UM ATRATIVO TURÍSTICO

AMAZÔNICO DE BELÉM (PA)
Alan Carlos de Jesus Costa

Matheus Yuri de Oliveira Rosa

Flavio Henrique Souza Lobato

LOHMANN et al. 2009). Ademais, os próprios veículos requerem boa infraestrutura, segurança e comodidade durante toda a viagem (GAZONI; SILVA; FORTES, 2017; SILVA et al., 2020).

No que se refere ao contexto de Belém (PA), capital do Estado do Pará - situada na região amazônica, ao norte do Brasil -, cidade cercada por ilhas e entrelaçada por rios e igarapés, apresenta grandes potencialidades para o modal de transporte fluvial (hidroviário) e para o turismo (FERREIRA; VACA, 2008, 2017). Contudo, o principal modal de transporte utilizado é o terrestre (rodoviário), tal fato faz com que o potencial fluvial dessa região não seja aproveitado e dinamizado, sendo este utilizado, normalmente, por pequenas embarcações que realizam o transporte de passageiros ou de mercadorias entre as ilhas próximas e a cidade de Belém (e vice-versa) (MEGUIS, 2018; RODRIGUES, 2018), como é o caso da Ilha do Combu. Essas embarcações, no entanto, apresentam estados estruturais visivelmente em precariedade, o mesmo ocorre com os terminais de embarque e desembarque - os quais não atendem às exigências de segurança, estrutura e acessibilidade, conforme dispõe o Código de Obras e Edificações do Município de Belém (FERREIRA; VACA, 2017; MEGUIS; BAHIA, 2019; RODRIGUES, 2018, 2019; TOBIAS, 2007).

Diante deste cenário, este trabalho buscou investigar a seguinte questão: qual a avaliação do visitante sobre a infraestrutura de acesso (veículos e terminais) à ilha? Assim, o objetivo traçado foi o de avaliar a infraestrutura dos/nos terminais (portos de embarque e de desembarque) e dos veículos (meios de transporte) utilizados nos deslocamentos de passageiros até o Combu, tendo como base as avaliações dos próprios usuários sobre seis itens (aspectos) - os quais foram mensurados com base na escala Likert de pontuação, a saber: 1 - Péssimo, 2 - Ruim, 3 - Regular, 4 - Bom e 5 - Excelente (MALHOTRA, 2001). Os dados foram tabulados e analisados a partir do Microsoft Office Excel por meio da estatística descritiva, considerando as médias de avaliação dos usuários do transporte utilizado para o acesso à ilha.

Para uma melhor organização, convém esclarecer que este trabalho se encontra estruturado em seis seções. Esta primeira faz uma breve apresentação, descrevendo o objetivo do trabalho, a problemática e o objeto de estudo da pesquisa. Na segunda seção, se traz os procedimentos metodológicos de coleta e de análise de dados. A terceira seção faz breves discussões sobre o turismo e os transportes, destacando a importância de cada um deles, bem como do planejamento integrado entre eles para o desenvolvimento do turismo e das cidades onde a atividade se estabelece. Na quarta seção, se situa o objeto e o contexto em que a pesquisa está inserida. A quinta, traz os resultados que puderam ser evidenciados e as discussões, análises e discussões realizadas entre os dados e os referenciais teóricos utilizados. A sexta seção, por fim, traz as considerações finais do estudo. 
A AVALIAÇÃO DO VISITANTE SOBRE A

INFRAESTRUTURA DE TRANSPORTE À ILHA

DO COMBU, UM ATRATIVO TURÍSTICO

AMAZÔNICO DE BELÉM (PA)
Alan Carlos de Jesus Costa Matheus Yuri de Oliveira Rosa Flavio Henrique Souza Lobato

\section{Metodologia}

Para viabilizar esta pesquisa, os autores se fundamentaram em uma abordagem mista: qualitativa e quantitativa, de cunho descritivo, sendo empregadas como técnicas de investigação as pesquisas bibliográfica, documental e de campo. Esta última foi realizada no principal porto de acesso à ilha, localizado na Praça Princesa Izabel, em Belém, e em dois portos de desembarque na ilha. Como ferramentas de coleta de dados se utilizaram de observações do lócus da pesquisa e da aplicação de questionário avaliativo. Este último foi aplicado nos dias 16 e 18 de dezembro de 2016 - pois era um período de alta temporada da atividade -, junto a 50 (cinquenta) pessoas, entre homens e mulheres maiores de 18 anos que nesses dias frequentavam a ilha. Dividido em duas partes, o instrumento inicialmente foi composto por perguntas acerca de aspectos socioeconômicos com o objetivo de qualificar os sujeitos. Posteriormente, as perguntas buscavam captar avaliações referentes às condições estruturais dos portos de embarque e desembarque e das embarcações, bem como dos trabalhadores que realizam o transporte de passageiros para a Ilha do Combu.

A tabulação e a análise dos dados foram efetuadas a partir da escala Likert, que consiste uma escala psicométrica, comumente utilizada em abordagens quantitativas, uma vez que permite mensurar as avaliações dos participantes da pesquisa a partir de um valor atribuído a determinados aspectos sob investigação (MALHOTRA, 2001). As respostas dos respondentes poderiam ir de 1 a 5 pontos, sendo: 1 - Péssimo; 2 - Ruim; 3 - Regular; 4 - Bom e; 5 - Excelente. Os dados foram sistematizados e analisados a partir do Microsoft Office Excel, por meio de estatística descritiva, considerando as médias de avaliação dos usuários do transporte utilizado para o acesso à ilha. No entanto, para a mensuração dos resultados, a média das respostas seguiu os parâmetros presentes no Quadro 1.

Quadro 1. Parâmetros de avaliação da qualidade do transporte

\begin{tabular}{|c|c|c|c|}
\hline Nível & Avaliação & Pontuação & Classificação \\
\hline 1 & Péssimo & De 0 a 1,9 pontos & \\
\hline 2 & Ruim & De 2 a 2,9 pontos & \\
\hline 3 & Regular & De 3 a 3,9 pontos & \\
\hline 4 & Bom & De 4 a 4,9 pontos & \\
\hline 5 & Excelente & 5 pontos & \\
\hline
\end{tabular}

Observatório de Inovação do Turismo - Revista Acadêmica

Vol. XIV, $\mathrm{n}^{\circ} 3$, dezembro - 2020 
A AVALIAÇÃO DO VISITANTE SOBRE A

INFRAESTRUTURA DE TRANSPORTE À ILHA

DO COMBU, UM ATRATIVO TURÍSTICO

AMAZÔNICO DE BELÉM (PA)
Alan Carlos de Jesus Costa

Matheus Yuri de Oliveira Rosa

Flavio Henrique Souza Lobato

Desse modo, foram realizados cálculos acerca dos pesos e das médias de todos os respondentes, de modo que quanto mais próximo do 5 mais bem avaliado foi o item e, quanto mais próximo do 1 , menos bem avaliado foi o item. Foram 6 os itens avaliados, quais sejam: 1) Porto de embarque, 2) Quantidade de embarcações, 3) Segurança nas embarcações, 4) Quantidade de passageiros por embarcação, 5) Portos de desembarque e 6) Atendimento e preparo técnico dos pilotos das embarcações. No mais, importa esclarecer que foi realizada uma Média Geral de Avaliação (MGA), a fim de conceber uma dimensão mais ampla e integrada da avaliação da infraestrutura dos veículos e dos terminais de acesso à ilha, a partir da percepção dos visitantes que participaram da pesquisa.

\section{Turismo e transportes: breve considerações}

À efetivação da atividade turística estão envolvidos diversos setores, os quais se entrecruzam e se desdobram de maneira intrínseca e extrínseca, afetando direta e indiretamente diferentes segmentos - economia, política, cultura, meio ambiente etc. Esses setores se expressam desde a preparação para a viagem de um turista, perpassando pelo acesso e pela utilização da infraestrutura básica e turística (BENI, 2003; BOULLÓN, 2002). Ademais, eles são quem criam as condições necessárias para a consolidação dos melhores tipos de serviços, quais sejam: acesso, acomodação, entretenimento, alimentação e, sobretudo, os transportes. Portanto, eles são condição sine qua non para a motivação e a realização de deslocamentos e para materialização da atividade turística (PELIZZER, 1978). No bojo dessa discussão, Silva (2008) destaca que as evoluções do turismo e dos transportes estão estreitamente atreladas, visto que o desenvolvimento dos transportes, enquanto fator facilitador de acesso, criador de novas rotas e promotor de mobilidade, oportunizou a eclosão do turismo pelo mundo (MILL; MORRISON, 1985).

À vista disso, os transportes possibilitaram que os destinos e suas respectivas atrações sejam acessíveis aos turistas, ao fornecer "[...] ligação entre o destino e a origem [e] facilita[r] o movimento de pessoas" (GAZONI; SILVA; FORTES, 2017, p. 2050). Em outras palavras, portanto, os transportes podem ser conferidos como elementos de composição, iniciação, fluidez e integração dos diferentes agentes componentes do produto e, sobretudo, do sistema turístico, uma vez que o transporte permite o acesso da demanda turística aos produtos ou serviços de uma destinação (oferta), de conformidade com a literatura especializada (BENI, 2003; BOULLÓN, 2002; LOHMANN, 2003; LOHMANN, FRAGA; CASTRO, 2013; MILL; MORRISON, 1985; RODRIGUE; COMTOIS; SLACK, 2013; SILVA et al., 2020). 
A AVALIAÇÃO DO VISITANTE SOBRE A

INFRAESTRUTURA DE TRANSPORTE À ILHA

DO COMBU, UM ATRATIVO TURÍSTICO

AMAZÔNICO DE BELÉM (PA)
Alan Carlos de Jesus Costa

Matheus Yuri de Oliveira Rosa

Flavio Henrique Souza Lobato

Nessa direção, a Organização Mundial do Turismo (OMT, 2001) assinala que aos transportes estão envoltos pelo menos sete componentes da oferta turística, são eles: Alojamento; Agências de Viagens e Turismo, Operadores e Guias de Turismo; Alimentos (Restauração) e Bebidas; Transportes; Rent-a-cars (que consiste no serviço de locação de veículos por curtos períodos, normalmente demarcados pelo sistema de venda de diárias); Serviços Culturais; e Serviços de Lazer e Recreação. Portanto, o setor de transportes, dentro do universo turístico, assume caráter essencial, dado que, para além de promover a acessibilidade, diminuir distâncias e tempo, ele estabelece um maior acesso e integração entre diferentes destinações turísticas, o que corrobora para uma maior e mais profícua circulação de pessoas e de mercadorias, seja na atividade turística, seja em outros setores da economia (GAZONI; SILVA; FORTES, 2017; LOHMANN, FRAGA; CASTRO, 2013). Portanto, os transportes, segundo Gazoni, Silva e Fortes (2017), compreendem um dos pilares basilares para o desenvolvimento do turismo.

Poon (1993), nessa perspectiva, atribui a massificação da atividade em diversos lugares ao avanço tecnológico dos transportes. A integração entre os destinos e o desenvolvimento da atividade turística, porém, somente se tornam possíveis ante a existência de diferentes meios de transporte. Cooper et al. (2002) sinalizam que existem quatro meios de transporte básicos, a saber: o rodoviário, o aquático (hidroviário e marítimo), o aéreo e o ferroviário. Cada um desses meios de transporte assume um papel importante e diferenciado de acordo com as particularidades existentes em cada viagem e em cada destino, como: os aspectos do meio físico, a distância da localidade, o tempo gasto na viagem, a estrutura do meio de transporte que inclui comodidade e segurança, além do preço e do serviço ofertado, dentre outros aspectos (LOHMANN, 2003; SILVA, 2008). Tal multiplicidade de formas de deslocamento implica diferentes formas de desenvolvimento do turismo, sobretudo ante as especificidades geoambientais dos destinos, como aponta Riveira (2018) ao analisar o turismo fluvial como alternativa para o desenvolvimento da atividade turística em municípios do rio Magdalena, na Colômbia, da mesma forma que Marques (2019) discorre sobre o impacto do turismo fluvial no desenvolvimento da região demarcada do Alto Rio Douro, em Portugal.

Cooper et al. (2002) elencam a existência e a importância da ciência e da diferenciação dos elementos básicos que compõem o mundo dos transportes, são eles: a Via que consiste no meio físico podendo ser de natureza artificial (ferrovias e rodovias) ou natural (ar e água) - utilizado por um determinado meio de transporte para a realização da viagem, a Unidade de Transporte ou Modal: se configura como o meio de transporte, o veículo propriamente utilizado (carro, barco, avião, etc.); a Força Motriz: é o componente utilizado para gerar movimento ao veículo, podendo ser gerada naturalmente, por intermédio da força gerada pelo ser humano, pelos ventos, etc.; ou artificialmente,

Observatório de Inovação do Turismo - Revista Acadêmica

Vol. XIV, nº 3, dezembro - 2020 
A AVALIAÇÃO DO VISITANTE SOBRE A

INFRAESTRUTURA DE TRANSPORTE À ILHA

DO COMBU, UM ATRATIVO TURÍSTICO

AMAZÔNICO DE BELÉM (PA)
Alan Carlos de Jesus Costa

Matheus Yuri de Oliveira Rosa

Flavio Henrique Souza Lobato

com os motores de barcos, carros a vapor, entre outros e o Terminal: que é o espaço onde se encontra o veículo que será utilizado na viagem, sendo também uma conexão entre as diferentes vias e unidades de transportes ou modais. Silva (2008) pontua que estes componentes básicos dos transportes, destacados por Cooper et al. (2002), por si só, não apresentam a concepção clara do que de fato seriam os transportes turísticos. Nesse sentido, Palhares (2003, p. 27) esclarece que o transporte turístico pode ser entendido:

[...] como a atividade/meio que interliga a origem de uma viagem turística a um determinado destino (e vice-versa), que interliga vários destinos turísticos entre si (primários e secundários) ou o que faz com que os visitantes se desloquem dentro de um mesmo destino primário ou secundário.

Desse modo, concomitantemente, os transportes turísticos exercem papel facilitador e figuram como “[...] condição fundamental para o desenvolvimento de qualquer destino em que as ações de intervenção no sistema de transporte reflete na qualidade do turismo, sobretudo na circulação de pessoas e bens" (GAZONI; SILVA; FORTES, 2017, p. 2050). Tal discussão somente reitera a essencialidade que os transportes têm durante a implementação e o desenvolvimento da atividade turística (LOHMANN, 2003; MOREIRA; SANTOS, 2016). Todavia, em hipótese alguma se deve deixar de levar em consideração, durante o processo de estruturação do turismo, o planejamento e o ordenamento dos transportes (e vice-versa), tendo em vista que eles têm influência marcante nos demais serviços urbanos de uma cidade, os quais podem também compor o produto turístico (LOHMANN, FRAGA; CASTRO, 2013).

Palhares (2003) acentua o debate assinalando ser imprescindível que se tenha o conhecimento claro e sistemático da importância dos transportes no turismo e do turismo nos transportes, pois, durante a fase de planejamento dos transportes, por vezes, se estabelecem grandes limitações. Nesses casos, comumente, os planejadores dessa área levam em consideração única e exclusivamente as disposições técnicas da sua área de atuação, negligenciando as normas e condições de outras áreas envoltas ao processo (TOBIAS, 2007). Assim, não é incomum se observar a ausência de integração e de conexão de informações, bem como se evidenciar ações parceladas e contraditórias, não havendo, portanto, o intercruzamento de contribuições, o que resulta em esforços fragmentados, dispersos e frustrados em conjunto (LOHMANN, FRAGA; CASTRO, 2013). No bojo desta discussão, cumpre salientar que o planejamento dos transportes se trata de um conjunto de ações que abordam a "[...] estrutura de circulação (rodovias e ferrovias), inclusive pontos de acesso e conexões, normalmente em horizontes médios e longos, o que requer o uso de técnicas de previsão [...]", conforme dispõe Vasconcellos (2000, 
p. 54). Logo, o planejamento fragmentado, ao invés de contribuir com o turismo, acaba obliterando, ele próprio, o desenvolvimento da atividade.

Silva (2008, p. 18), nesse sentido, pontua algumas de deficiências típicas do planejamento dos transportes e do turismo no Brasil, em especial na Amazônia, ao discorrer que grande parte dos pontos de acesso somente se moderniza e se desenvolve quando o aumento dos fluxos turísticos (a demanda) compreende uma realidade. Noutros termos, o autor explica que os intervenientes dos terminais (gestores e operadores turísticos) não investem na realização de estudos de monitoramento, a fim de prognosticar e diagnosticar tendências - os quais servem como base para as discussões, os planejamentos e as ações emergenciais de prevenção ou soluções (LOHMANN, FRAGA; CASTRO, 2013). Silva (2008, p. 18) conclui sua análise dizendo que, “[...] a política é reativa e não proativa [...]” e que essas deficiências podem desencadear o decréscimo dos fluxos turísticos e comprometer a experiência do turista.

\section{Transporte fluvial entre Belém (PA) e suas ilhas}

A cidade de Belém é cercada e entrelaçada por rios, igarapés e muitas ilhas. Segundo pesquisas anteriores, realizadas por Ferreira e Vaca (2008), a Lei do Município de Belém de número 7.682/1994, a cidade de Belém compreende 39 ilhas, se encontram localizadas, sobretudo, no Rio Guamá e na Baía do Guajará. Esses locais são onde normalmente residem as populações tradicionais, as quais, apesar da separação pelo rio, possuem uma relação estreita e direta com a população do centro de Belém, tendo em vista que alguns gêneros alimentícios são retirados do interior dessas ilhas e transportados pelos ribeirinhos em pequenas embarcações para a urbe (FERREIRA; VACA, 2017). No mais, os ribeirinhos mantêm essa relação por utilizarem muitos dos serviços presentes exclusivamente no centro urbano, dado que fazem parte do município de Belém (RODRIGUES, 2018, 2019).

Nesse sentido, os principais modais de transporte característicos da cidade de Belém são o rodoviário e o hidroviário (FERREIRA; VACA, 2017; MEGUIS, 2018; SILVA, 2008; TOBIAS, 2007). Embora 2/3 do município de Belém seja formada por ilhas (GUERRA, 2015), a predominância de utilização dos transportes é terrestre, cuja frota vem aumentando significativamente ao longo dos anos, mas a própria malha rodoviária da Região Metropolitana de Belém (RMB) não vem acompanhando esse crescimento, o que vem causando transtornos para a população local, sobretudo numerosos e extensos congestionamentos (SILVA, 2008; TOBIAS, 2007). Por outro lado, no que concerne ao transporte fluvial, este vem sendo negligenciado, não apresentando estrutura, segurança e fiscalização adequadas, nem mesmo grandes investimentos, pois esse modal é utilizado praticamente pela população que reside 
nas ilhas, a qual historicamente é excluída de políticas públicas urbanas em Belém (FERREIRA; VACA, 2017; SILVA, 2008; TOBIAS, 2007).

Diante deste panorama, autores como a Ferreira e Vaga (2008, p. 03) assinalam que:

[...] Demos a costa para o rio e com isso esquecemos de uma população que faz parte de Belém e que está excluída da vida urbana e de todo o serviço oferecido na cidade (saúde, educação, informação). Esta é uma realidade presente principalmente nas ilhas Sul (cerca de 2000 hab) que fazem parte da RMB (Combu, Murutucum, Maracujá, Ilhinha, Juçara, Papagaio e Ilha Grande). São lugares em que pulsam modos de vida que diferem significativamente do padrão caracterizado como urbano. Lugares espacialmente próximos da metrópole e ao mesmo tempo tão longe de seu estilo de vida.

Com o caos que o trânsito da cidade tem passado, pesquisadores e sociedade civil têm visto o rio com um enorme potencial de transporte de passageiros e mercadorias, sendo apontado como a solução do caótico trânsito do centro de Belém. No entanto, o transporte fluvial na Amazônia possui uma série de deficiências que impossibilitam a sua dinamização (FERREIRA; VACA, 2017; TOBIAS, 2007), bem como o desenvolvimento local por meio do turismo (MEGUIS; BAHIA, 2019). Silva (2008), ao realizar um estudo acerca da Amazônia, e Meguis (2018), ao pesquisar o deslocamento fluviomarítimo de Belém a Soure no Marajó (PA), disserta que os entraves da implementação de um transporte fluvial de qualidade na região perpassa, dentre outras questões, pela precariedade de infraestruturas dos portos (terminais) e das embarcações (veículos), assim como pelo despreparo dos recursos humanos em ofertar serviços com respeito e bem receber aos passageiros.

\section{Resultados e discussões: a avaliação do visitante sobre a infraestrutura de transporte à Ilha do Combu, Belém (PA)}

Nos últimos anos, a Área de Proteção Ambiental (APA) Ilha do Combu tem sido a "menina dos olhos" do turismo da capital paraense, Belém, tendo em vista que as singularidades características do bioma Amazônia estão vivas nessa ambiência tão próxima do centro urbano. A ilha dispõe de um diferencial paisagístico natural e cultural que a cidade de Belém vem perdendo com a inserção de grandes projetos de intervenção urbana. Por assim ser, a ilha tem sido frequentada tanto por turistas quanto por locais - que se deslocam até esse espaço em face da nostalgia dos tempos e do status cabocloribeirinho que a cidade possuía. No entanto, ante o modal fluvial não ser desenvolvido na região pelas políticas públicas (MEGUIS, 2018; SILVA, 2008; TOBIAS, 2007), a infraestrutura dos terminais e das embarcações que estabelecem o acesso à ilha não atendem aos anseios da população local e dos visitantes (FERREIRA; VACA, 2017; RODRIGUES, 2019). 
A AVALIAÇÃO DO VISITANTE SOBRE A

INFRAESTRUTURA DE TRANSPORTE À ILHA

DO COMBU, UM ATRATIVO TURÍSTICO

AMAZÔNICO DE BELÉM (PA)
Alan Carlos de Jesus Costa

Matheus Yuri de Oliveira Rosa

Flavio Henrique Souza Lobato

Diante disso, este trabalho buscou avaliar a qualidade da infraestrutura de transportes com vistas a contribuir com a mensuração e a cientificização das noções que trasladam no senso comum. Inicialmente, esta pesquisa buscou conhecer rapidamente o perfil daqueles que se dispuseram contribuir com a investigação, dado que os resultados dependem diretamente do público respondente. Por assim ser, entre os 50 respondentes que compuseram a amostra do estudo, após a validação das respostas, $58 \%$ eram do sexo masculino e $42 \%$ do sexo feminino. Entre elas e eles, $24 \%$ possuíam de 18 a 20 anos, 22\% de 21 a 25 anos, $20 \%$ de 26 a 30 anos, $10 \%$ de 31 a 40 anos e $24 \%$ deles tinham idades acima de 40 anos. Destes, $60 \%$ moravam em Belém, 26\% residiam em outros municípios do Estado do Pará e apenas 14\% eram de outros estados do país, consoante dispõem os dados elencados na Tabela 1.

Tabela 1. Perfil socioeconômico dos visitantes da Ilha do Combu que participaram da pesquisa

\begin{tabular}{l|l|c|c}
\hline \multirow{3}{*}{ Dados socioeconômicos } & $n$ & $\%$ \\
\hline \multirow{4}{*}{ Faixa-etária } & Feminino & 21 & $42 \%$ \\
\cline { 2 - 4 } & Masculino & 29 & $58 \%$ \\
\cline { 2 - 4 } & De 18 a 20 anos & 12 & $24 \%$ \\
\cline { 2 - 4 } & De 21 a 25 anos 26 a 30 anos & 11 & $22 \%$ \\
\cline { 2 - 4 } & De 31 a 40 anos & 10 & $20 \%$ \\
\cline { 2 - 4 } & Mais de 40 anos & 12 & $24 \%$ \\
\hline \multirow{5}{*}{ Origem } & Belém & 30 & $60 \%$ \\
\cline { 2 - 4 } & Outros municípios do Pará & 13 & $26 \%$ \\
\cline { 2 - 4 } & Outros estados do Brasil & 7 & $14 \%$ \\
\hline
\end{tabular}

Fonte: Elaborado pelos autores a partir da pesquisa de campo (2016)

No estudo mais recente de Rodrigues (2019), foi possível identificar uma diferenciação quanto à origem dos visitantes, uma vez que 54,5\% eram originários de outros estados, 25,8\% eram de Belém, 9,1\% da RMB, 7,6\% de municípios do interior do estado e apenas 3\% eram estrangeiros. Tais percentuais de visitantes, segundo a autora, ajudam a definir o Combu como local turístico: pois há a presença de turistas (CRUZ, 2001). Sob outra perspectiva, a partir de percepções evidenciadas em campo $^{5}$, foi possível constatar uma clara diferenciação sobre as motivações de visitação da ilha.

5 Esta é uma constatação da experiência dos autores como visitantes e enquanto pesquisadores da ilha. Embora essa mesma reflexão possa estar inserida em trabalhos semelhantes, é importante ressaltar que ela nasceu a partir dos debates para a construção deste trabalho. Nesse

Observatório de Inovação do Turismo - Revista Acadêmica 
A AVALIAÇÃO DO VISITANTE SOBRE A

INFRAESTRUTURA DE TRANSPORTE À ILHA

DO COMBU, UM ATRATIVO TURÍSTICO

AMAZÔNICO DE BELÉM (PA)
Alan Carlos de Jesus Costa

Matheus Yuri de Oliveira Rosa

Flavio Henrique Souza Lobato

Enquanto alguns visitantes, especialmente aqueles que residem no Estado do Pará (visitante interno), buscam, por vezes, se conectar com a cultura caboclo-ribeirinha, com a cultura amazônica, que está ameaçada diante das novas dinâmicas e lógicas da vida moderna. Por outro lado, outros visitantes, normalmente os turistas de outros locais do país (visitante externo), comumente, visitam a ilha com um olhar estereotipado, colonial e/ou etnocêntrico, o qual está visitando um modo de vida muito "primitivo", "pobre", "coitado", "atrasado", "exótico" - esse olhar lembra muito a perspectiva dos portugueses quando chegaram ao Brasil e entraram em contato com os indígenas e seus modos de vida particulares, bem como lembra a concepção de "sociedades primitivas" que os primeiros antropólogos construíram ao investigar culturas para além da "Europa civilizada".

Após conhecer um pouco sobre o perfil dos respondentes da pesquisa, se buscou avaliar os seguintes itens acerca do transporte até a Ilha do Combu: 1) Porto de embarque; 2) Quantidade de embarcações; 3) Segurança nas embarcações; 4) Quantidade de passageiros por embarcação; 5) Portos de desembarque e 6) Atendimento e preparo técnico dos condutores das embarcações.

\subsection{Porto de embarque na Praça Princesa Isabel}

Neste item, após a sistematização dos dados, se evidenciou que os visitantes consideram o Porto de embarque "Ruim" $(2,6)$. A maioria entende que a infraestrutura do Porto da Praça Princesa Isabel é ruim em razão da ausência de segurança, acessibilidade, posto de informações acerca da ilha e dos horários para saída dos barcos, ausência de um ponto de espera adequado e problemas estruturais visíveis no porto, os quais podem pôr em risco a vida de passageiros. Adicionalmente, por ser um espaço completamente desamparado pelas autoridades governamentais, serve de abrigo e/ou refúgio para pedintes, usuários de drogas e infratores. Por estes motivos, a expressiva maioria dos entrevistados dá preferência pela utilização de carros de passeios próprios ou táxis para chegar à Praça Princesa Isabel, preferindo ficar dentro dos automóveis até o momento de saída do barco, uma vez que o local é, segundo eles, inseguro.

Nesse cenário, Boullón (2002) salienta que a infraestrutura é basilar para desenvolvimento da atividade turística, afinal, é complicado tornar o turismo realidade em uma cidade com infraestrutura deficiente ou ausente. Nesse debate, Silva et al. (2020, p. 132) assinalam que “[...]a menor ou maior concentração de infraestrutura de transportes nos municípios determina que um exerça influência

sentido, torna-se clara a valiosa contribuição das observações sistemáticas e das "conversas informais" em campo enquanto instrumentos de coleta de dados qualitativos.

Observatório de Inovação do Turismo - Revista Acadêmica

Vol. XIV, $n^{\circ} 3$, dezembro - 2020 
A AVALIAÇÃO DO VISITANTE SOBRE A

INFRAESTRUTURA DE TRANSPORTE À ILHA

DO COMBU, UM ATRATIVO TURÍSTICO

AMAZÔNICO DE BELÉM (PA)
Alan Carlos de Jesus Costa

Matheus Yuri de Oliveira Rosa

Flavio Henrique Souza Lobato

relevante sobre os demais, em termos de atração de recursos produtivos e de atração de viagens". Esse panorama, porém, é recorrente no Brasil, uma vez que a história do país revela que “[...] o desenvolvimento da infraestrutura setorial não foi suficiente para responder de maneira adequada às necessidades advindas do processo de expansão da economia e crescimento do setor turístico no país" (SILVA et al., 2020, p. 139). Em face disso, segue-se a lógica "rudimentar" de diversas Políticas Públicas de Turismo do país: de que é necessário haver demanda para pensar a oferta de bens e serviços de qualidade (SILVA, 2008).

\subsection{Quantidade de embarcações}

No que concerne aos meios de transporte utilizados para o trajeto até a ilha, cumpre ressaltar que as viagens não são operacionalizadas por empresas, mas pela Cooperativa de Transporte Escolar e Alternativo das Ilhas de Belém (COOPETRANS) e, também, por duas associações de condutores de embarcações, sendo uma delas a Associação dos Trabalhadores do Transporte Marítimo de Passageiros das Ilhas de Belém e do Baixo Acará (ASTIB) (RODRIGUES, 2018). Logo, o acesso ao Combu é realizado por condutores que vivem nas ilhas ou em bairros próximos ao Porto da Praça Princesa Isabel. No início, havia muitos conflitos entre os motoristas para transportar os passageiros, porém, a partir de reuniões entre os "barqueiros", ficou acordado que haveria uma ordem de travessia, tornando mais justo o processo. Diante disso, ao avaliar o quantitativo de embarcações, a média das respostas obtidas na avaliação foi "Regular" $(3,06)$. Segundo os visitantes, o quantitativo de barcos e de lanchas que operam as viagens é suficiente para atender a demanda de passageiros.

Para além da qualidade infraestrutural das embarcações, a quantidade disponibilizada é condição essencial no turismo, tendo em vista que a otimização da atividade é decorrente da conformação simultânea de uma rede de transportes hierárquica e complexa, de conformidade com Lohmann, Fraga e Castro (2013) e com Rodrigue, Comtois e Slack (2013). Dito de outro modo, para que os transportes possam atender às demandas inerentes ao turismo, eles dependem " $[. .$.$] da viabilidade$ e da atratividade de um destino, e um destino depende de transporte para o acesso dos turistas, este constituído como um sistema importante no desenvolvimento dos destinos. Uma estrutura impulsionadora de desenvolvimento" (GAZONI; SILVA; FORTES, 2017, p. 2058). Em face disso, além da oferta disponibilizada fomentar à atração turística na ilha, este aumento no volume de fluxo tem oportunizado aos condutores a geração de renda para a suas famílias, como ocorre em diversos destinos mundiais (LOHMANN, 2003). Este processo figura como um dos benefícios intrínsecos à atividade, o qual é incitado pelo efeito multiplicador do turismo (BENI, 2003).

Observatório de Inovação do Turismo - Revista Acadêmica

Vol. XIV, nº 3, dezembro - 2020 
A AVALIAÇÃO DO VISITANTE SOBRE A INFRAESTRUTURA DE TRANSPORTE À ILHA DO COMBU, UM ATRATIVO TURÍSTICO AMAZÔNICO DE BELÉM (PA)

\subsection{Segurança nas embarcações}

Ao se considerar o item segurança das embarcações, os visitantes da ilha avaliaram como sendo "Ruim" $(2,8)$. Para eles, os veículos são muito pequenos e grande parte deles não possui equipamentos de segurança para todos os passageiros. Em alguns poucos casos, visitantes relataram que em outros momentos presenciaram barcos com os motores expostos, sem a proteção para evitar acidentes, como o escalpelamento. Desse modo, a média das respostas ("Ruim" $=2,8$ ) revela que muitos passageiros se sentem inseguros durante toda a travessia, não sendo incomum casos de pessoas que não visitam a ilha por sentir medo de acidentes. Em abordagem semelhante, Rodrigues (2019) identificou que o transporte fluvial é um dos aspectos que precisam de melhorias, sendo apontado por 38,1\% ( $\mathrm{n}=24)$ dos visitantes.

De acordo com a autora mencionada, conquanto o acesso ao Combu seja “[...] de grande importância para o uso tanto de moradores quanto de visitantes, vem se apresentando de maneira desigual e conflituosa, visto que muitos barcos não apresentam equipamentos de segurança adequados aos passageiros" (RODRIGUES, 2019, p. 411). Tal cenário é facilmente observado no relato a seguir de uma internauta na página de avaliação do Google e revela, a partir da indignação e da frustração de uma turista, como o acesso ao Combu necessita de maiores investimentos:

[...] decidi ir até a Praça Princesa Isabel, para conferir a travessia para a ilha do Combu que seria no dia seguinte (domingo). Lá encontrei uma grande precariedade, tanto no local quanto nas embarcações. Estas são pequenas e não usam nenhum equipamento de segurança. Quando questionei sobre coletes, a moça saiu para perguntar à dona da embarcação e não mais retornou com a resposta. [...] Mesmo tendo garagem paga na praça, para deixar o carro, resolvemos não ir. Estavam comigo mais 6 pessoas e não quis colocar nossas vidas em risco. Abortei a ilha do Combu do meu roteiro! Fiquei muito frustrada pelo tempo que dediquei pesquisando todos os restaurantes [...] (Informação escrita por M. O., acessada em Google).

No contexto da atividade turística, a sensação de segurança é um fator determinante, pois, conforme Silva (2008), se o turista ou excursionista não se sente seguro em uma destinação ou em um atrativo turístico, ele certamente terá uma experiência traumática, não retornará ao local e nem indicará ele positivamente a outros potenciais visitantes (MARUJO, 2008). Destarte, é notável a urgência de um planejamento integrado entre destinos turísticos e transportes, conforme propõem Lohmann, Fraga e Castro (2013).

Observatório de Inovação do Turismo - Revista Acadêmica

Vol. XIV, $\mathrm{n}^{\circ} 3$, dezembro - 2020 
A AVALIAÇÃO DO VISITANTE SOBRE A

INFRAESTRUTURA DE TRANSPORTE À ILHA

DO COMBU, UM ATRATIVO TURÍSTICO

AMAZÔNICO DE BELÉM (PA)
Alan Carlos de Jesus Costa Matheus Yuri de Oliveira Rosa Flavio Henrique Souza Lobato

\subsection{Quantidade de passageiros por embarcação}

No que se refere à quantidade de passageiros por embarcação, a média das respostas $(3,26)$ avalia esse item como "Regular", pois, conforme vários visitantes, o número de passageiros dentro das embarcações está de acordo com o que é permitido. Comumente, os barqueiros respeitam o limite de lotação dos barcos e das lanchas, tendo em vista que há constantes fiscalizações das autoridades competentes (Capitania dos Portos) e dos próprios usuários, os quais se negam ir em pé durante a travessia. Ressalta-se que as lanchas têm capacidade máxima de 12 pessoas e os barcos, dependendo do porte, entre 15 e 25 pessoas - antes e durante o embarque todos os passageiros são instruídos sobre a obrigatoriedade do uso de coletas salva-vidas. Não obstante a lotação dos veículos, as travessias dependem da ocupação dos restaurantes da ilha, dado que, uma vez atingida a capacidade máxima, as travessias são, por ora, encerradas, a fim de evitar acidentes e garantir a segurança e o atendimento dos visitantes nos restaurantes. Tais limitações são primordiais para o respeito à Capacidade de Carga Turística (CCT) da Ilha do Combu, isto é, o limite de visitas que esse atrativo pode receber e suportar, numa dada temporalidade (dias, semana, mês), antes de ocorrer perturbações irreversíveis ao meio físico, biológico, social e cultural (PIRES, 2005).

\subsection{Porto de desembarque na ilha}

Ao se abordar sobre a infraestrutura de desembarque na ilha, convém salientar que cada restaurante possui o seu espaço de desembarque de passageiros, uns mais bem equipados e aparentemente seguros, outros não. Em uma avaliação geral, a média das respostas dos entrevistados $(2,6)$ revelou que os visitantes consideram o item portos de desembarque "Ruim", pois, de maneira geral, os portos não possuem infraestrutura adequada, não sendo acessíveis e seguros aos seus visitantes. Nesse cenário, salienta-se que a precariedade dos portos de embarque e de desembarque de acesso ao Combu - assim como apontam estudos em outros lugares do mundo (MARQUES, 2019; RIVEIRA, 2018) -, oblitera e, por vezes, inviabiliza o desenvolvimento local pelo turismo (RODRIGUES, 2018, 2019), afinal, não são acessíveis aos usuários -sendo incomum inclusive observar visitantes idosos e PCDs nos passeios à ilha. As fragilidades da infraestrutura de transportes, portanto, incitam à exclusão de pessoas que fazem parte de grupos com limitações físicas (FERREIRA; VACA, 2017; MEGUIS; BAHIA, 2019). 
A AVALIAÇÃO DO VISITANTE SOBRE A

INFRAESTRUTURA DE TRANSPORTE À ILHA

DO COMBU, UM ATRATIVO TURÍSTICO

AMAZÔNICO DE BELÉM (PA)
Alan Carlos de Jesus Costa Matheus Yuri de Oliveira Rosa Flavio Henrique Souza Lobato

\subsection{Atendimento e preparo técnico dos condutores das embarcações}

Sobre os responsáveis pelo transporte, com média 2,4, a avaliação dos entrevistados considerou "Ruim" o atendimento e o preparo técnico dos "barqueiros". Para os visitantes, embora os trabalhadores tenham muitos anos de experiência, vasto conhecimento sobre a embarcação e o movimento dos rios, muitos deles agem com imprudência em algumas viagens, o que não transmite confiança e segurança aos usuários. Durante uma das travessias, um dos passageiros (participantes da pesquisa), chamou atenção para o modo como o senhor pilotava o barco: "Olhem só. Ele está pilotando o barco com os pés, isso não passa confiança alguma para o turista, meninos" (Figura 1). Segundo os usuários apontam, alguns condutores não tratam com cordialidade os passageiros, não há um serviço de informações turísticas, sobretudo quanto aos horários de saída e de chegada, aos cuidados durante a viagem e às demais instruções relacionadas à segurança. Diante desse cenário, evidencia-se que os barqueiros precisam de capacitações e de treinamentos constantes para o bem receber dos visitantes (RODRIGUES, 2018).

Figura 1. Responsável pelo transporte manobrando com o pé.

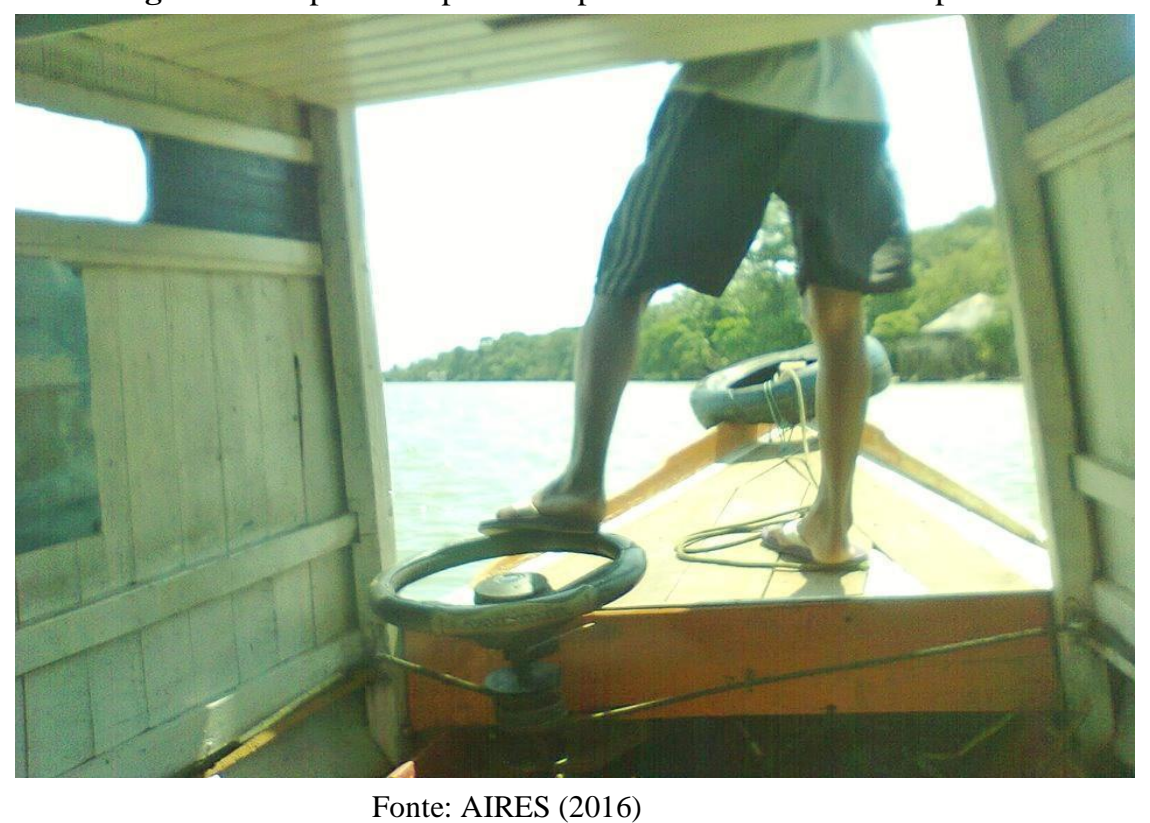

\subsection{Avaliação geral dos visitantes}

Finalmente, após o tratamento dos dados, calculou-se a Média Geral de Avaliação (MGA) dos terminais e dos meios de transporte para acesso ao Combu, a qual resultou na MGA 2,38 (Ruim). À vista disso, ficou evidente que a infraestrutura básica, tanto dos portos quanto das embarcações, deixa a

Observatório de Inovação do Turismo - Revista Acadêmica

Vol. XIV, $\mathrm{n}^{\circ} 3$, dezembro - 2020 
A AVALIAÇÃO DO VISITANTE SOBRE A

INFRAESTRUTURA DE TRANSPORTE À ILHA

DO COMBU, UM ATRATIVO TURÍSTICO

AMAZÔNICO DE BELÉM (PA)
Alan Carlos de Jesus Costa

Matheus Yuri de Oliveira Rosa

Flavio Henrique Souza Lobato

desejar, os aspectos mais precários são: segurança, acessibilidade e comodidade. A condição estrutural dos portos e dos barcos foi considerada precária, a falta de segurança e a acessibilidade dos/nos portos e nas embarcações são apontadas como um dos principais pontos negativos do deslocamento realizado, conforme demonstram os dados na Tabela 2. De posse de tais resultados, constata-se que, para além da Região Amazônica (FERREIRA; VACA, 2017; MEGUIS, 2018; SILVA, 2008), o restante do país lida com problemáticas semelhantes e recorrentes que obliteram o desenvolvimento local e turístico concomitante das destinações (GAZONI; SILVA; FORTES, 2017; LOHMANN, FRAGA; CASTRO, 2013; SILVA et al., 2020; VASCONCELLOS, 2000).

Tabela 2. Resultado das avaliações dos visitantes da Ilha do Combu em dezembro de 2016

\begin{tabular}{l|c|c|c|c|c}
\hline \multicolumn{1}{c|}{ Itens avaliados } & $\begin{array}{c}\text { Péssimo } \\
(\mathbf{0}-\mathbf{1 , 9})\end{array}$ & $\begin{array}{c}\text { Ruim } \\
(\mathbf{2}-\mathbf{2 , 9})\end{array}$ & $\begin{array}{c}\text { Regular } \\
(\mathbf{3}-\mathbf{3 , 9})\end{array}$ & $\begin{array}{c}\text { Bom } \\
(\mathbf{4}-\mathbf{4 , 9})\end{array}$ & $\begin{array}{c}\text { Excelente } \\
(\mathbf{5})\end{array}$ \\
\hline 1. Porto de embarque & & $\mathbf{2 , 6}$ & & & \\
\hline 2. Quantidade de embarcações & & & $\mathbf{3 , 0 6}$ & & \\
\hline 3. Segurança nas embarcações & & $\mathbf{2 , 8}$ & & & \\
\hline $\begin{array}{l}\text { 4. Quantidade de passageiros por } \\
\text { embarcação }\end{array}$ & & & $\mathbf{3 , 2 6}$ & & \\
\hline $\begin{array}{l}\text { 5. Porto de desembarque } \\
\text { 6. Atendimento e preparo técnico } \\
\text { dos condutores das embarcações }\end{array}$ & & $\mathbf{2 , 4}$ & & & \\
\hline Média Geral de Avaliação (MGA) & & $\mathbf{2 , 3 8}$ & & & \\
\hline
\end{tabular}

À luz dos resultados apresentados, se entende que as avaliações realizadas pelos usuários são negativas para a dinamização do turismo na ilha, tendo em vista que os visitantes costumam partilhar com outras pessoas as suas experiências de viagens. Nessa esteira, normalmente, a internet se configura como o principal espaço de compartilhamento dessas vivências (MARUJO, 2008), tendo os relatos de viagem no Instagram, no Facebook, em blogs e em sites, despontado como os maiores geradores de conteúdo e engajamento (FRAGA; BORGES; BOTELHO, 2019; ROSA; SILVA; LOBATO, 2020). Acerca disso, foi encontrado, durante as pesquisas na internet para construção deste trabalho, um depoimento muito interessante sobre a visita de um turista à Ilha do Combu. Em seu blog, Ohana (2011, s. p.) discorre que:

Observatório de Inovação do Turismo - Revista Acadêmica

Vol. XIV, $n^{\circ} 3$, dezembro - 2020 
[...] De manhã cedo fui ao cais do bairro Condor, local de partida da viagem. Ao chegar, me surpreendi com o abandono do local: estacionamentos irregulares, calçadas defasadas e ausência de seguranças. Procurei alguma orientação turística, mas só encontrei um "flanelinha" dando dicas sobre a embarcação. Mesmo assim, a vista pitoresca do rio Guamá me fez ter esperança de um passeio inesquecível. Após esperar aproximadamente dez minutos, embarquei no rústico navio "pô-pô-pô". Garanti logo meu salva-vidas por prevenção e aproveitei a viagem. [...] O turismo é essencial para nossa região, porém, essas situações o distanciam de ser devidamente explorado. Não adianta ter belezas naturais sem infraestrutura adequada para usufruílas.

Em consequência, muitas pessoas, sobretudo os turistas que não estão acostumados com tal realidade e a veem sendo manchada a partir das frustrações de outras pessoas, deixam de visitar a Ilha do Combu. Logo, se percebe que, embora a ilha seja capaz de motivar o deslocamento de visitantes, para os entrevistados, devido à falta ou à deficiência de planejamentos e incentivos governamentais adequados, os meios de se chegar à ilha acabam se constituindo como um dos problemas que dificultam o público interessado em visitar e, com efeito, fomentar o turismo na ilha, visto que, como retrodito, os transportes e os portos utilizados apresentam condições estruturais deficitárias (FERREIRA; VACA, 2017; RODIGUES, 2019).

No caso específico dos participantes da pesquisa que residem em Belém (60\%), mesmo diante dos entraves de acesso, esses mantêm as visitas ao Combu por conceberem-no como um espaço de rompimento do que é vivido no cotidiano, consoante relatou um visitante: "Uma oportunidade de 'refúgio' do caos da cidade. Um lugar onde podemos estar em contato com a natureza, desfrutar de uma boa paisagem e da nossa maravilhosa comida paraense, com excelentes opções de peixes. Recomendadíssimo!” (Informação escrita por F. A., acessada em Google). Seria a vivência na ilha, portanto, a fuga do cotidiano: o "anticotidiano", de acordo com Krippendorf (2001). Dessa maneira, os visitantes pontuaram que os serviços, a gastronomia, e a infraestrutura dos restaurantes, a hospitalidade dos prestadores de serviços, a contemplação da paisagem, o contato mais próximo com a natureza, por serem satisfatórios, "eufemizam", de certa forma, os problemas enfrentados no deslocamento até a ilha, pelo menos até a volta.

De acordo com as sugestões comentadas pelos entrevistados, para o melhor desenvolvimento da atividade turística na ilha, se destaca: a disposição de placas de informação no porto, a melhoria da infraestrutura dos portos (área de embarque e desembarque) e das embarcações, a segurança, a maior divulgação do local e dos restaurantes, o estabelecimento de horários nas saídas e nas chegadas das embarcações, a melhora nos locais de banho dentro da área dos restaurantes, a coleta seletiva de lixo, a promoção de cursos profissionalizantes para a população local, o tratamento da água e a melhor organização e articulação dos moradores locais. Estas indicações de melhorias - semelhantes às

Observatório de Inovação do Turismo - Revista Acadêmica

Vol. XIV, n $^{\circ}$, dezembro - 2020 
A AVALIAÇÃO DO VISITANTE SOBRE A

INFRAESTRUTURA DE TRANSPORTE À ILHA

DO COMBU, UM ATRATIVO TURÍSTICO

AMAZÔNICO DE BELÉM (PA)
Alan Carlos de Jesus Costa

Matheus Yuri de Oliveira Rosa

Flavio Henrique Souza Lobato

encontradas no estudo de Rodrigues (2019) -, cada uma ao seu modo e dentro de um planejamento integrado e coeso (LOHMANN, FRAGA; CASTRO, 2013; SILVA et al., 2020), podem certamente fomentar o aumento do fluxo de visitantes e, paralelamente, construir um desenvolvimento local pelo turismo na ilha.

\section{Considerações finais}

Os transportes em Belém se tratam de uma questão emblemática, não apenas pela mobilidade urbana da cidade se encontrar em um estado de calamidade, mas também porque os rios - quando usados como vias de tráfego, seja entre os ribeirinhos, seja por visitantes e turistas que visitam a região insular da urbe - carecem de infraestrutura e de fiscalização. Diante disso, este trabalho buscou investigar a avaliação dos visitantes sobre a infraestrutura de acesso (veículos e terminais) à Ilha do Combu, tendo em vista que nos últimos anos ela tem sido um importante atrativo turístico da capital paraense. Constatou-se, a partir dos resultados obtidos nas respostas dos visitantes, uma avaliação negativa (Ruim $=2,38$ ), com insatisfação em relação à negligenciada infraestrutura do terminal e das embarcações utilizadas no acesso à ilha. Com efeito, as avaliações dos usuários demonstram que a infraestrutura de acesso se configura como o grande empecilho para o desenvolvimento local e para a melhoria das atividades turísticas na ilha.

Não obstante, de forma recorrente, os visitantes mostraram-se insatisfeitos com a estrutura dos locais de desembarque, pois não apresentavam itens básicos de segurança e de acessibilidade. No mais, não existem locais apropriados para a espera dos transportes, bem como posto de informação para o esclarecimento de possíveis dúvidas e questões relacionadas à ilha e à travessia. No entanto, os visitantes ressaltaram que a APA compreende uma excelente ambiência para se conectar com a natureza, sendo possível o divertimento com amigos e familiares com maior sossego e "distante" do estresse urbano, embora o Combu esteja apenas 15 minutos de distância do centro de Belém.

Destarte, para atenuar ou enveredar em direção à resolução da problemática em questão, é imprescindível que o Poder Público conceba um planejamento capaz de efetivar ações de melhoria da infraestrutura local e, igualmente, é indispensável a participação da comunidade local, a fim de oferecer um produto turístico de qualidade, ambientes seguros e com bons equipamentos e serviços capazes de sanar as exigências e as necessidades dos visitantes. Tais ações, decerto, irão contribuir com a visibilidade turística e a dinamização do número de visitas a esse paraíso natural - culminando na geração de emprego e renda para a comunidade local, por meio do efeito multiplicador do turismo. Entrementes, importa pontuar que o planejamento e a gestão do turismo precisam considerar a 
A AVALIAÇÃO DO VISITANTE SOBRE A INFRAESTRUTURA DE TRANSPORTE À ILHA

DO COMBU, UM ATRATIVO TURÍSTICO AMAZÔNICO DE BELÉM (PA)
Alan Carlos de Jesus Costa Matheus Yuri de Oliveira Rosa Flavio Henrique Souza Lobato

capacidade de carga da ilha, com vistas a evitar e/ou a minimizar os efeitos negativos dos impactos sociais, culturais, econômicos e, nomeadamente, os ambientais no modo de vida da população ribeirinha que (sobre)vive na e da ilha.

\section{Referências}

BENI. M. C. Análise estrutural do turismo. 9. ed. São Paulo: SENAC, 2003.

BOULLÓN, R. C. Planejamento do espaço turístico. Tradução: Josely Vianna Baptista. Bauru/SP: Edusc, 2002.

COOPER, C. et al. Turismo: princípios e práticas. 2a . ed. São Paulo: Bookman. 2002.

CRUZ, R. D. C. A. Introdução à geografia do turismo. São Paulo: Roca, 2001.

FERREIRA, R. C. B.; VACA, L. E. A. Esse rio é a minha rua: a circulação e o agrupamento dos ribeirinhos na Amazônia Oriental. E-metropolis, [S. 1], v. 29, n. 8, p. 205-211, 2017.

FERREIRA, R. C. B.; VAGA, L. E. A. O espaço dividido: o caso do transporte hidroviário nas Ilhas Sul da Região Metropolitana de Belém - RMB. In: Seminário Internacional - Amazônia e Fronteiras do Conhecimento NAEA - Núcleo de Altos Estudos Amazônicos, Belém (PA), Anais... Belém: NAEA, 2008

FRAGA, C.; BORGES, V. L. B.; BOTELHO, E. S. O Bonde de Santa Teresa e o bairro da Lapa na cidade do Rio de Janeiro: análises com base nas online travel reviews. Revista Acadêmica Observatório de Inovação do Turismo, v. 13, n. 3, p. 135-152, 2019.

GAZONI, J. L.; SILVA, E. A. M. D.; FORTES, J. A. A. S. A oferta de transporte e a demanda turística no Brasil: uma análise de componente principal. Journal of Tourism \& Development, Aveiro, [s. v.], n. 27/28, p. 2049-2059, 2017.

GUERRA, G. A. D. Eidorfe Moreira and the insular aspect of Belém. Boletim do Museu Paraense Emílio Goeldi. Ciências Humanas, Belém, v. 10, n. 3, p. 583-589, 2015.

KRIPPENDORF, J. Sociologia do turismo: para uma nova compreensão do lazer e das viagens. São Paulo: Aleph, 2001.

LOHMANN, G. et al. From hub to tourist destination - an explorative study of Singapore and Dubai's Aviation-Based Transformation. Journal of air Transport Management, [S. 1], v. 15, [s. n.], p. 205$211,2009$.

LOHMANN, G. The role of transport in tourism development: nodal functions and management practices. International Journal of Tourism Research, [S. 1], v. 5, [s. n.], p. 403-407, 2003.

LOHMANN, G.; FRAGA, C.; CASTRO, R. Transportes e destinos turísticos: planejamento e gestão. Rio de Janeiro: Elsevier/Campus, 2013.

Observatório de Inovação do Turismo - Revista Acadêmica

Vol. XIV, n $^{\circ}$ 3, dezembro - 2020 
A AVALIAÇÃO DO VISITANTE SOBRE A

INFRAESTRUTURA DE TRANSPORTE À ILHA

DO COMBU, UM ATRATIVO TURÍSTICO

AMAZÔNICO DE BELÉM (PA)
Alan Carlos de Jesus Costa Matheus Yuri de Oliveira Rosa Flavio Henrique Souza Lobato

MALHOTRA, N. Pesquisa de marketing: uma orientação aplicada. Porto Alegre: Bookman, 2001.

MARQUES, A. R. F. D. C. O impacto do turismo fluvial no desenvolvimento da Região

Demarcada do Alto Douro Vinhateiro: o caso dos Navios Hotel. 116 f. Dissertação (Mestrado em Gestão de Turismo) - Instituto Politécnico do Cávado e do Ave, Cávado e Ave, 2019.

MARUJO, M. N. N. V. A Internet como novo meio de comunicação para os destinos turísticos: o caso da Ilha da Madeira. Turismo em Análise, São Paulo, v. 19, n. 1, p. 25-42, 2008.

MEGUIS, T. R. B. Transporte fluviomarítimo e turismo: a viagem à Soure e as perspectivas de desenvolvimento local. Dissertação (Mestrado em Planejamento do Desenvolvimento) - Programa de Pós-Graduação em Desenvolvimento Sustentável do Trópico Úmido, Universidade Federal do Pará, Belém, 2018.

MEGUIS, T. R. B.; BAHIA, M. C. Transporte fluviomarítimo e turismo: a viagem a Soure e as perspectivas de desenvolvimento local. Papers Naea, Belém, v. 28, n. 3, p. 178-195, 2019.

MILL, R.C.; MORRISON, A. M. The tourism system: an introductory text (Tradução dos autores). New Jersey, Estados Unidos: Editora Prentice Hall, 1985.

MOREIRA, C. O.; SANTOS, N. P. D. River tourism in Portugal: touristic offer and potentials. In: NUNES, A.; MOREIRA, C. O.; PAIVA, I. R.; CUNHA, L. S. D. Water territories. Coimbra: Centro de Estudos de Geografia e Ordenamento do Território da Universidade de Coimbra, 2016. p. 225-271.

OHANA, L. Blog Lucas Ohana. Cotidiano [Internet]. Desabafo de um visitante - Ilha do Combu. Lucas Ohana. 2011, jun. Disponível em: http://lucasohana.wordpress.com/2011/06/17/desabafo-deum-visitante-ilha-do-cumbu/. Acesso em: 12 maio 2019.

ORGANIZAÇÃO MUNDIAL DO TURISMO. Introdução ao turismo. São Paulo: Roca, 2001.

PADILHA, O. La T. El turismo: fenómeno social, 1992.

PALHARES, G. L. Transporte aéreo e turismo: gerando desenvolvimento socioeconômico. São Paulo: Aleph, 2003.

PELIZZER, H. A. Uma introdução à técnica do turismo e transportes. São Paulo: Livraria Pioneira, 1978.

PÉREZ, X. P. Turismo cultural: uma visão antropológica. 1. ed. Tenerife: Colección PASOS edita, 2009.

PIRES, P. S. "Capacidade de carga" como paradigma de gestão dos impactos da recreação e do turismo em áreas naturais. Revista Turismo em Análise, São Paulo, v. 16, n. 1, p. 5-28, 2005.

POON, A. Tourisme, technology and competitives strategies. CAB International, Oxon. 1993 
A AVALIAÇÃO DO VISITANTE SOBRE A INFRAESTRUTURA DE TRANSPORTE À ILHA

DO COMBU, UM ATRATIVO TURÍSTICO AMAZÔNICO DE BELÉM (PA)
Alan Carlos de Jesus Costa Matheus Yuri de Oliveira Rosa Flavio Henrique Souza Lobato

RIVEIRA, N. G.Turismo fluvial: una alternativa para fomentar la actividad turística en los municipios ribereños al río Magdalena. El caso del municipio de Suárez (Tolima, Colombia). Revista Turismo y Sociedad, Colômbia, v. 23, n. 2, p. 149-182, 2018.

RODRIGUE, J. P.; COMTOIS, C.; SLACK, B. The geography of transport systems. ed. 3. Oxon: Routledge, 2013.

RODRIGUES, Á. F. A. C. A produção do espaço pelo e para o turismo na área de proteção ambiental da Ilha do Combu (Belém-Pará). Dissertação (Mestrado em Planejamento do Desenvolvimento) - Programa de Pós-Graduação em Desenvolvimento Sustentável do Trópico Úmido, Universidade Federal do Pará, Belém, 2018.

RODRIGUES, Á. F. A. C. Consumo na e da natureza: políticas ambientais e práticas de turismo na ilha do Combu. Papers Naea, Belém, v. 28, n. 3, p. 400-418, 2019.

ROSA, L. C. B. L.; SILVA, V. B.; LOBATO, F. H. S. A comunicação turística digital do local ao global: uma avaliação de sites oficiais de turismo. Turismo: Estudos \& Práticas (UERN), Mossoró/RN, v. 9, n. 1, p. 1-18, 2020.

SILVA, E. A. M. D. et al. Consolidação do Turismo em pequenos municípios brasileiros: nuances e oportunidades na rede de transportes. Rosa dos Ventos - Turismo e Hospitalidade, Caxias do Sul, v. 12, n. 1, p. 129-153, 2020.

SILVA, F. R. D. O. E. Transportes turísticos na Amazônia: problemas e soluções dos principais pontos de acesso para a região. 324 f. Dissertação (Mestrado) - Departamento de Economia, Gestão e Engenharia Industrial, Universidade de Aveiro, Aveiro, 2008.

TOBIAS, M. S. G. Transporte hidroviário urbano em Belém: realidade e perspectivas. Revista dos Transportes Públicos, São Paulo, v. 29, [s. n.], p. 59-68, 2007.

TRIGO, L. G. G. Turismo básico. 6. ed. São Paulo: Editora Senac São Paulo, 1998.

VASCONCELLOS, E. Transporte urbano, espaço e equidade. Ed. 1. São Paulo: Annablume, 2000. 